\title{
Pemanfaatan Teknologi Augmented Reality untuk Media Pengenalan Huruf Alfabet pada Anak Usia Dini
}

\author{
Estu Sinduningrum ${ }^{1 *}$, Atiqah Meutia Hilda ${ }^{1}$, dan Rosalina ${ }^{1}$ \\ ${ }^{1}$ Universitas Muhammadiyah Prof. DR. Hamka J1. Tanah Mardeka, Jakarta Timur, Indonesia \\ *Email: estu.ningrum@uhamka.ac,id
}

\begin{abstract}
Abstrak
Saat ini banyak orang tua mulai mengajarkan anaknya membaca sejak dini di rumah, ataupun menyekolahkannya di Taman Kanak - Kanak (TK) yang mengajarkan membaca. Metode yang sesuai untuk Pendidikan Anak Usia Dini (PAUD) adalah belajar sambil bermain. Metode ini tidak membebani dan tidak ada unsur paksaan. Pemanfaatan Augmented Reality untuk media pengenalan membantu anak belajar membaca dengan menggunakan cara yang menyenangkan, yaitu dengan memindai marker berisi huruf atau suku kata menggunakan kamera perangkat Android. Nantinya akan muncul video animasi, audio pelafalan, dan hewan 3D sesuai huruf atau suku kata dan gambar dalam marker yang dipindai. Desain ini kemudian diimplementasikan dalam sebuah aplikasi untuk sistem operasi Android. Uji coba aplikasi ini dilakukan dengan kedua mitra dari Lab School Permata UHAMKA dan Baitul Ulum Al Isfahani Manfaluthi yang dihadiri oleh para Guru dan Orang Tua Wali murid. Peserta mencoba langsung aplikasi dan memberikan feedback untuk mengetahui sejauh mana aplikasi dapat membantu proses Pembelajaran. Berdasarkan hasil evalusi aplikasi ini terbukti dapat membantu Guru dan orang tua wali murid untuk mempraktekan model belajar Alfabet yang asik dan menyenangkan untuk anak dan muridnya.
\end{abstract}

Kata kunci: PAUD, Augmented Reality, Marker, Android

\begin{abstract}
Today, many parents begin to teach their children to early read at home or to educate them at kindergarten school that teaching them to read. The appropriate method of early childhood education are learning while playing. There is no overload and force in this method. Implementation of augmented reality as an introduction media can help children to read happily by scanning the marker that contain of letter or syllables use camera in android software. Animation video, pronunciation audio and $3 D$ animal will appear later in accordance with the letter or syllables and picture in scanned marker. This design then is implemented in an application of android system. The test of this application was done with both of mitra from Lab School Permata UHAMKA and Baitul Ulum Al Isfahani Manfaluthi attended by teachers and the parents of student guardians. The participant tried to use the application directly and give the feedback how far the application could help the process of learning. Based on evaluation result, this application could help teacher and the parents of guardian student to practice the alphabet learning model fun and happily for student and children.
\end{abstract}

Keywords: Early Child, Augmented Reality, Marker, Android

Format Sitasi: Sinduningrum E., Hilda A.M., \& Rosalina R. (2019). Pemanfaatan Teknologi Augmented Reality Untuk Media Pengenalan Huruf Alfabet Pada Anak Usia Dini. Jurnal Solma, 08(1), 142-149. Doi: http://dx.doi.org/10.29405/solma.v8i1.3151

Diterima: 30 Januari 2019 | Revisi: 21 April 2019 | Dipublikasikan: 30 April 2019. 


\section{PENDAHULUAN}

Dewasa ini teknologi berkembang dengan cepat, perkembangan ini menjadikan teknologi sebagai alat untuk membantu manusia dalam segala bidang. Salah satu bentuk dari perkembangan teknologi yaitu Augmented Reality. Augmented Reality atau AR adalah suatu teknologi yang menggabungkan benda maya dua dimensi atau tiga dimensi ke dalam sebuah lingkungan nyata lalu menampilkan benda-benda maya tersebut secara real time. Teknologi Augmented Reality (AR) adalah bentuk perkembangan teknologi multimedia yang sangat menarik karena membuat user merasa asyik dan terhibur menikmati teknologi sekaligus mendapat informasi konten yang bermanfaat.

PAUD (Pendidikan anak usia dini) adalah pendidikan prasekolah yaitu pendidikan dimana anak belum memasuki pendidikan formal. PAUD diterapkan pada anak usia 0 hingga 6 tahun, dimana rentang usia dini merupakan saat yang tepat dalam mengembangkan potensi dan kecerdasan anak (CHA \& Damayanti, 2005). Penyerapan pengetahuan anak pada usia dini dilakukan dengan cara bermain. Namun permainan anakanak hendaknya dapat digunakan sebagai suatu cara untuk melatih motorik halus dan motorik kasar anak untuk memaksimalkan potensi pada diri anak sejak usia sedini mungkin. Bentuk permainan yang dapat menunjang aktifitas belajar anak dalam usia perkembangannya adalah permainan edukatif atau yang sering disebut sebagai edu game. Untuk menciptakan alat permainan yang sesuai dengan kebutuhan anak diperlukan suatu metode pendekatan sentra. Pendekatan Sentra adalah pendekatan penyelenggaraan Pendidikan Anak Usia Dini yang berfokus kepada anak yang dalam proses pembelajarannya berpusat di sentra main. Di sisi lain perkembangan jenis permainan anak menggunakan teknologi komputer juga telah banyak mengalami perkembangan. Augmented reality salah satu teknologi komputer yang dapat diterapkan dalam permainan anak. Augmented reality adalah suatu teknologi yang menggabungkan dunia virtual ke dalam dunia nyata ((M. Budi, 2010). Dengan teknologi AR, permainan edukatif menjadi lebih menarik dan menyenangkan, karena obyek virtual ditampilkan dalam bentuk yang seolah-olah nyata, cara mengoperasikan permainan ini pun tidak sulit. Selain itu dengan Augmented reality anak-anak secara tidak langsung diperkenalkan dengan teknologi komputer sejak usia dini. Dengan teknologi AR anak-anak hanya akan berinteraksi dengan marker saja, sehingga terbilang cukup aman. Bagi para tenaga didik pun akan lebih mudah mengawasi anak didiknya dalam bermain. Dengan menghadirkan obyek virtual ke dalam dunia nyata, anak-anak akan diajak berimajinasi untuk meningkatkan daya kreatifitasnya. 
Obyek dalam dunia nyata tidak dapat dimanipulasi seperti layaknya obyek virtual. Disinilah AR berperan untuk menampilkan obyek virtual langsung layaknya obyek pada dunia nyata, namun dapat dimanipulasi selayaknya pada obyek virtual, seperti manipulasi waktu, ukuran, maupun bentuk. Untuk itu perlu adanya pengenalan inovasi baru tersebut dalam dunia permainan anak-anak khususnya anak usia dini, dimana usia dini merupakan usia emas (golden ages), usia yang sangat berpengaruh dalam tumbuh dan kembang anak.

\section{MASALAH}

Proses pembelajaran di Paud dan TK anak-anak saat pelajaran mengenal huruf alphabet dirasa belum bisa maksimal, karena masih ada anak-anak yang masih sulit untuk konsentrasi dan pola fikir mereka yang masih tahap bermain (Pebriani, 2012). Oleh karena itu, diharapkan dengan menggunakan teknologi AR ini maka metode belajar huruf yang masih konvensional menggunakan media belajar membaca buku yang dirasakan oleh anakanak masih membosankan, akan dapat menarik minat bagi anak-anak Paud dan TK.

Huruf adalah sesuatu yang abstrak bagi anak-anak pada usia dini. Pada proses pengenalan huruf dan kata anak-anak khususnya pada kedua mitra, guru dan orang tua perlu untuk memahami tahapan-tahapannya. Disebabkan huruf merupakan sesuatu yang abstrak, maka diperlukan perlakuan khusus pada tahap pengenalannya. Dengan memperhatikan kemampuan anak dalam menghafal dan ketika proses belajar yang dilakukan. Apakah anak lebih menyukai gambarnya daripada hurufnya, ataukah anak susah untuk mengingat huruf yang ditanyakan kepadanya. Setelah itu, ujilah kemampuannya untuk membaca suku kata, lalu dilanjutkan dengan menguji kemampuan anak untuk membaca kata per kata.

Dari wawancara dan pengamatan yang dilakukan pada kedua mitra yang ternyata masih memakai media buku belajar membaca, banyak sekali anak usia TK yang justru malah kabur ketika belajar mengenal huruf dan kata. Sebagian anak bersembunyi di area bermain dan sebagiannya lagi hanya memandangi buku tanpa mau serius untuk belajar (Polina \& Pramudiani, 2018). Segala sesuatu yang sifatnya abstrak itu mempunyai tingkat kesulitan yang tinggi, sehingga diperlukan cara yang kreatif agar anak-anak bisa menguasai materi abstrak dengan lebih mudah. Kegiatan pembelajaran telah menggunakan media berupa kartu gambar yang ada kata nama dari gambar, kartu suku kata, kartu huruf dan kartu gambar yang ada kata dari nama gambar yang dipenggal katanya menjadi suku kata. 
Masa anak-anak merupakan masa bermain dan belajar. Pembelajaran yang dilakukan oleh pendidik atau orang tua harus diupayakan memasukan aktivitas bermain yang menyenangkan. Bila unsur bermain tidak ada, maka anak akan mudah bosan dan malas untuk mengikuti pembelajaran yang akan diberikan oleh pendidik atau orang tua. Demikian dengan unsur pengenalan huruf dan kata juga dimasukkan unsur-unsur permainan sehingga anak-anak senang belajar dan membaca, maka muncul suatu ide dengan memanfaatkan teknologi augmented reality. Penggunaan Teknologi Augmented Reality ini memungkinkan setiap anak dapat belajar sambil bermain, agar proses pengenalan huruf dan kata yang kurang menyenangkan dapat diminimalisasi, sehingga dalam proses pengenalan huruf dan kata ini menjadi lebih menyenangkan dan menarik (Emilia, Kamayani, \& Gunawan, 2018) .

\section{METODE PELAKSANAAN}

Berdasarkan permasalahan yang dihadapi tersebut, maka solusi yang kami tawarkan adalah melakukan pelatihan Augmented Reality untuk media pengenalan huruf alphabet pada usia dini. Dengan memberikan bekal pengetahuan dan keterampilan kepada guruguru dan orang tua murid dalam bidang TIK (Teknologi Informasi dan Komunikasi), khususnya dalam hal penggunaan software aplikasi Augmented Realty berbasis android. Serta memberikan bekal Pengetahuan Pemanfaatan Handphone bagi perkembangan anak Usia Dini. Berikut uraian dalam pelaksanaannya:

1. Persiapan, pada tahap ini tim dan mitra melakukan kesepakatan untuk waktu pelaksanaan dan keikutsertaan peserta, pengecekan kesiapan tempat, peralatan dan koneksi jaringan wifi (mengantisipasi peserta yang tindak berlangganan paket data) disesuaikan dengan minat dan karakteristik yang sudah mereka fahami dan senangi dan menyiapkan materi dan perlengkapannya.

2. Pelaksanaan, Pemateri memberikan gambaran dasar teori teknologi Augmented Reality dan kegunanaannya dalam membantu proses pembelajaran anak usia dini khususnya pengenalan huruf alphabet dan tutorial melakukan instalasi software aplikasi berbasis android "Pengenalan Huruf Alfabet", dan memberi contoh bagaimana cara penggunaannya

3. Evaluasi, yang dilakukan merupakan umpan balik bagi para guru dan wali murid, sehingga mereka dapat langsung mempraktekkan pengunaan teknologi Augmented Reality tersebut, pada Smartphone dengan system operasi Android jelly bean 4.1 yang mereka miliki. 


\section{HASIL DAN PEMBAHASAN}

Setelah menerima tanggapan yang cukup antusias dari Lab School PAUD Permata UHAMKA \& Baitul Ulum Al Isfahani Manfaluthi atas kesediaannya dalam pelaksanaan kegiatan pengabdian ini. Berdasarkan jadwal yang telah ditetapkan pelaksanaan kegiatan dilakukan di 2 tempat mitra. Untuk minggu pertama dilaksanakan di Lab School PAUD Permata UHAMKA yang dihadiri oleh 11 guru dan minggu ke dua dilaksanakan di Baitul Ulum Al Isfahani Manfaluthi yang dihadiri oleh 4 guru dan 14 orang tua wali murid.

Sebelum acara pembukaan tim melaksanakan Pretest sejauh mana para guru dan orang tua wali murid mengenal teknologi AR dilanjutkan share aplikasi AR. Hasil yang diperoleh hampir sebagian besar belum bias mempergunakannya. Kegiatan pelatihan untuk Lab School PAUD Permata UHAMKA dibuka langsung oleh Kepala Program Studi PAUD UHAMKA ibu Amelia Vinayastri, S.Psi., M.Pd. \& Baitul Ulum Al Isfahani Manfaluthi dibuka langsung oleh Kepala sekolah Ibu Yati Lismawati,S.Pd.

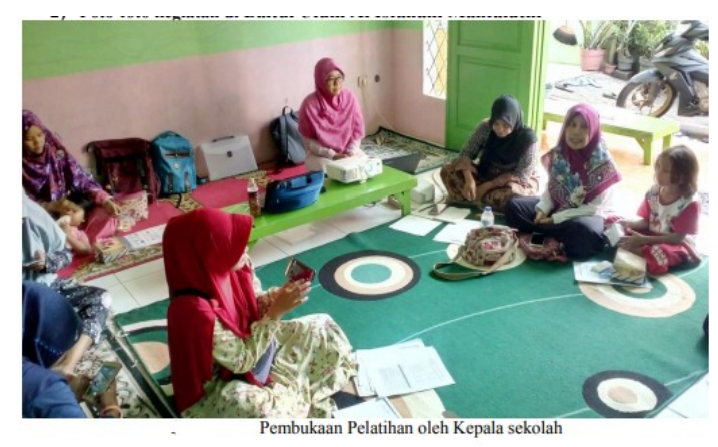

Gambar 1. Pembukaan Kegiatan

Kegiatan Pelatihan diawali dengan Pembacaan Ayat Suci Al-Quran. Dilanjutkan memberikan materi Pengenalan Teknologi Augmented Realty (AR) \& Pemanfaatan Dalam Dunia Pendidikan yang disampaikan oleh Atiqah Meutia hilda, S.Kom., M.Kom. Materi berikutnya Manfaat \& Bahaya Penggunaan Handphone Bagi Anak Usia Dini yang disampaikan oleh ibu Rosalina, ST., MT. dengan durasi waktu 50 menit dilanjutkan tanya jawab. 


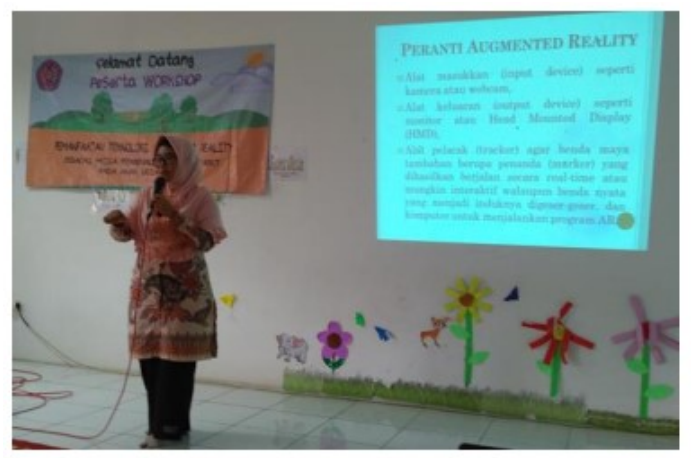

Gambar 2. Penyampaian Materi, Diskusi dan Tanya Jawab

Kegiatan sesi 2 materi yang disampaikan adalah Instalasi program AR Pada Handphone Peserta. Peserta dan Cara Penggunaan AR Sebagai Media Pembelajaran yang disampaikan oleh Estu Sinduningrum, S.T., M.T. Berdasarkan kebutuhan alat praktik yang telah dipersiapkan sebelumnya, yaitu: marker AR Huruf Alfabet, Marker AR Gambar dan Quota Internet . pemateri memberikan arahan langkah melakukan instalisasi Program AR dan membantu peserta mendownload aplikasi android di playstore peserta. Selanjutya menuntun cara menggunakan AR. Kamera yang dipergunakan peserta mendeteksi marker huruf dan gambar yang diberikan, kemudian setelah mengenali dan menandai pola marker webcam akan melakukan perhitungan apakah marker sesuai dengan database yang dimilki. Bila tidak maka informasi marker tidak akan diolah, tetapi bila sesuai maka informasi marker akan digunakan untuk me-render dan menampilkan objek 3D atau animasi yang telah dibuat sebelumnya.

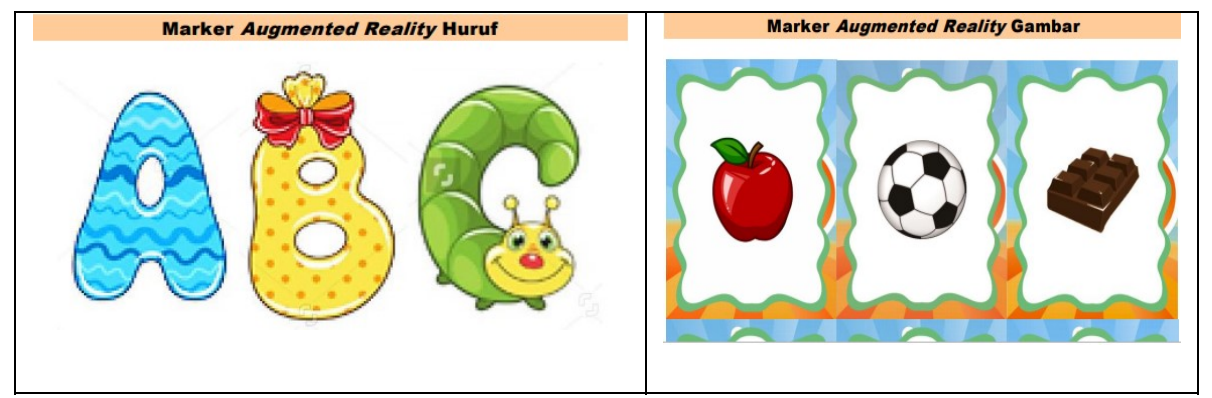

Gambar 3. Marker Augmented Reality

Setelah semua kegiatan di kedua tempat mitra, langkah selanjutnya adalah melakukan evaluasi. Evaluasi dilakukan berupa kuesioner dengan dua tahap, yaitu sebelum dan setelah pemberian materi dan pelatihan menggunakan handphone android. Kuesioner 
ini diharapkan bisa menjadi bahan evaluasi bagi pemateri. Pertanyaan kuesioner sebelum dan sesudah PKM.

Hasil dari kuesioner yang telah diberikan, yaitu: Sesi pertama. Kuesioner sebelum pkm bernilai 51.14\%, dari nilai tersebut dapat dikatakan bahwa hampir setengah dari peserta yang hadir belum mengetahui mengenai kegunaan teknologi augmented reality ini. Kuesioner sesudah pkm bernilai $81.82 \%$, dari nilai tersebut dapat dikatakan materi yang disampaikan adalah baik. Sesi kedua. Kuesioner sebelum pkm bernilai 58.93\%, dari nilai tersebut dapat dikatakan bahwa hampir setengah dari peserta yang hadir belum mengetahui mengenai kegunaan teknologi augmented reality ini. Kuesioner sesudah pkm bernilai 95.04\%, dari nilai tersebut dapat dikatakan materi yang disampaikan adalah sangatlah baik. Hasil Presentasi kegiatan PKM dapat dilihat pada Gambar 4.

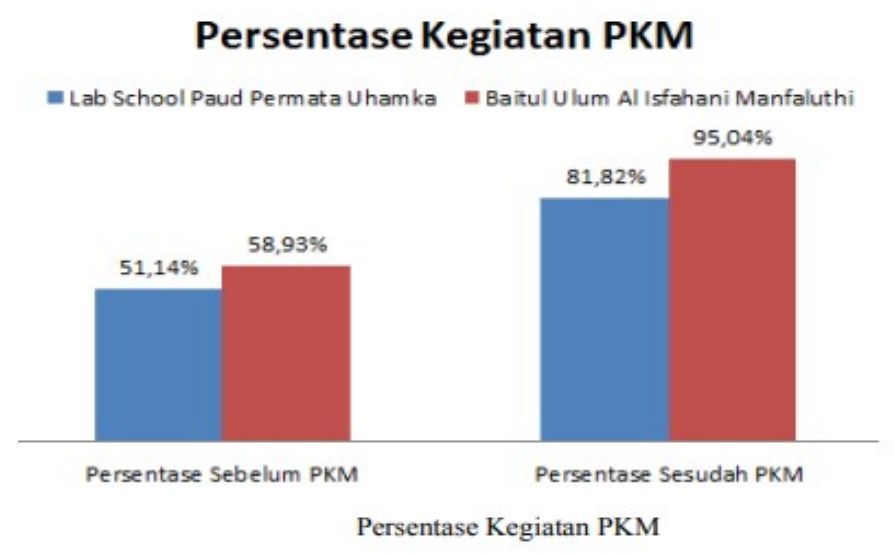

Gambar 4. Presentasi Kegiatan PKM

\section{KESIMPULAN}

1. Peserta pelatihan pada gelombang pertama adalah guru PAUD Uhamka (5 orang), guru TK anak Sholeh (3 orang), Guru PAUD Bintang (1 orang), Guru PDR (1 orang), dan Guru TK Kartika X-2 (1 Orang). Sedangkan pada gelombang kedua adalah Guru PAUD Baitul Ulum (4 orang), dan Wali Murid PAUD Baitul Ulum (17 orang).

2. Hasil questioner yang dilakukan mendapatkan nilai yang sangat baik dimana pada gelombang 1 didapatkan PAUD Uhamka nilai 81.82\% dan PAUD Baitul Ulum 95.04\% di gelombang kedua.

3. Dari hasil evaluasi yang berupa tugas, didapatkan hasil yang cukup baik, dimana terdapat peningkatan nilai dari nilai sebelum PKM (Pretest): PAUD Uhamka 51.14\%, 
Paud Baitul Ulum 58.93\% dan sesudah PKM (posttest): PAUD UHAMKA 81.82\%, Paud Baitul Ulum 95.04\%.

\section{UCAPAN TERIMA KASIH}

Ucapan terima kasih terutama ditujukan kepada pemberi dana kegiatan atau donatur. Ucapan terima kasih dapat juga disampaikan kepada pihak-pihak yang membantu pelaksanaan kegiatan.

\section{DAFTAR PUSTAKA}

CHA, W., \& Damayanti, D. R. (2005). Program Pendidikan Untuk Anak Usia Dini di Prasekolah Islam. Jakarta: Grasindo.

Emilia, R., Kamayani, M., \& Gunawan, P. H. (2018). Pelatihan Memantau Penggunaan Gadget pada Anak. Jurnal SOLMA.

M. Budi. (2010). "Kompasiana," Augmented Reality and Co. Augmented Reality and Co, 2905 2010. [Online]. Available: http://www.kompasiana.com/editaslim/kompasaugmented-realitymari-bermain-sekaligus-memanfaatkan realitasvirtual_54fd29a8a33311003d50f968. [Accessed 1303 2017].

Pebriani. (2012). Peningkatan Kemampuan Anak Mengenal Huruf Melalui Permainan Menguraikan Kata di Taman Kanak-kanak Negeri Pembina Agam. Pesona PAUD.

Polina, L., \& Pramudiani, P. (2018). Pembelajaran Karakter Melalui Media Dongeng pada PAUD Formal Binaan I dan Binaan III Ciracas Jakarta Timur. Jurnal SOLMA. https://doi.org/, [S.1.], v. 7, n. 2, p. 215-224, oct. 2018. ISSN 2614-1531. Available at: $<$ https://journal.uhamka.ac.id/index.php/solma/article/view/1665>. Date accessed: 02 may 2019. doi: https://doi.org/10.29405/solma.v7i2.1665.

\section{(c) (i)}

(C) 2019 Oleh authors. Lisensi Jurnal Solma, LPPM-Uhamka, Jakarta. Artikel ini bersifat open access yang didistribusikan di bawah syarat dan ketentuan Creative Commons Attribution (CC BY) license. (http://creativecommons.org/licenses/by/4.0/). 